\title{
Investigating the Relevance of Cultural Landscapes in Tourism Experience in Abeokuta
}

\author{
Ayeni, Dorcas A.* Adebiyi, Bolutito A. \\ Department of Architecture Federal University of Technology, Akure, Nigeria
}

\begin{abstract}
Tourism is a modern global phenomenon, and the synergy between this phenomenon and cultural landscapes has increased the demand at both local and international levels. This paper investigates the relationship between cultural landscape and tourism, especially in Abeokuta, Ogun State. This is on the premise of bringing about sustainable development in tourism, thereby enhancing the cultural and economic values of the site. The study is important as it provides a medium for the assessment of Abeokuta cultural landscapes, and relates the influencing factors with the assessment results. This was carried out through a critical review of existing literature on cultural landscapes and the inseparable link with tourism, as well as an empirical investigation using the quantitative method of data collection through questionnaire survey on all stakeholders in the tourism industry in Abeokuta. The data generated from the survey were analyzed and results were expressed in percentages. The findings revealed that cultural landscapes actually have a positive input regarding sustainable development, and also have immense contributions towards the wellbeing of man. It also brought to limelight, the factors contributing to the quality of landscapes in Abeokuta. The paper therefore strongly recommends that adequate information should be made available to all stakeholders to improve their interest and participation, which brings about effective management, and subsequently, sustainable tourism.
\end{abstract}

Keywords: Cultural Landscape, Abeokuta, Sustainable Tourism, Tourists Sites.

DOI: $10.7176 / \mathrm{JTHS} / 55-04$

Publication date:March $31^{\text {st }} 2021$

\section{Introduction}

The tourism industry is fast becoming one of the main emphasis for economic regeneration all around the world, and especially in developing countries, as a step to introduce variegation into the economy of such countries, as well as improving the quality of life of individuals (Ayeni, 2012). Emphasizing on the meaning of quality of life, Pacione (2003) stated that a quality life is not essentially a simple function of material wealth, but it refers either to the conditions of the environment that people live or to the attribute of the people themselves. Çakmak \& Çenesiz (2020) opined that tourism is very much essential in reducing poverty of individuals in developing countries, and improving economic growth alongside.

Landscape is perceived by researchers to be a phenomenon of which its description transcends that of a mere view. It also includes the features that distinguish an area from others, making the area stand out. These attributes are of importance to tourism experience (Ayeni, 2012). One major deduction from this description is the establishment of a relationship between the two variables - tourism and landscape. Naveh and Lieberman (2013) further described landscape as the totality of the human environment that consists of vivid, realistic and visible elements, forming a fusion between living organisms and the physical surface of the earth, as well as conscious, artistic creations of man. Both definitions show clearly that these areas are distinct; each with its entities, all of which sum up to attain the status of "landscape".

Over time, a close connection has always been existent between nature, people and their culture. The resultant phenomenon consists of sites, some of which reveal an attempt to sustain biological diversity, while others reflect some communal beliefs and customs. In line with these intentions, some of these sites, referred to as Cultural Landscapes have been included in the World Heritage List. (UNESCO WHC, 2018). According to Richards (2018) there has never been a time that we could separate culture from tourism. Recently though, their interrelationship has been identified in an explicit manner, thereby terming it Cultural Landscape. A cultural landscape can be seen as a subset of the bigger phenomenon known as Landscape. National Park Service (NPS) (2014) defined Cultural Landscape as "a geographic area, including both cultural and natural resources and the wildlife or domestic animals therein, associated with a historic event, activity, or person or exhibiting other cultural or aesthetic values". Time, as an element of the cultural landscape, is actively involved in the build-up of Cultural Landscape, which is the fusion between a natural environment and the involvement of a man. In this case, Time is viewed as the build-up of social practices layered in a cultural setting (Song, St. Clair, \& Wang, 2008).

Tourism, as described by Kaya (2002), is one of the most characteristic socio-economic phenomena in this era. The World Tourism Organisation provided a definition for Tourism as an activity done by an individual or a group, leading to a movement from a place to another, from a country to another for performing a specific task, for a maximum duration of one year (365 days), and a non-remunerated purpose (Jansirami and Mangai, 2013). 
The features that make up a good tourism sector are hinged on several attributes, which include the quality of the landscape, the diversity of the wildlife, including flora and fauna; the historic and cultural features and availability of tourism-supporting infrastructure and services (Ayeni, 2012). Also,

The Nations Encyclopedia (2018) considers tourism in Nigeria highly undeveloped, bearing in mind her available tourist resources, most especially, land, vegetation, and the various festivals. The available cultural landscapes make up the bedrock of the Nigerian tourism industry, but they seem inadequate in moving Nigeria to her desired spot in world tourism. As Bankole (2013) puts it, "Currently, there is a wide gap between Nigeria's vast tourism potential and actual performance". This conclusion stems from Nigeria's rankings of 131st out of 141 countries in 2015 and 129th out of 136 countries in 2017, in the lists showing tourism patronage rate in those countries by the World Economic Forum (WEF) (Crotti \& Misrahi, 2017). Nations Encyclopedia (2018) suggested barriers to a successful tourist industry to include "inconsistent regulations, security issues, widespread corruption and crime, crumbling roads and bridges, erratic telephone service, frequent shortage of fuel, electricity, and water, as well as social unrest in some parts of the country". Many locations in Nigeria, including Abeokuta, experience these anomalies, and they contribute largely to the relative paucity of visitors to the sites in question, and Nigeria as a whole.

Many of the tourist sites do not appeal to tourists to visit, also because of the level of deterioration that has taken place in them. This is partly due to the negligence of the stakeholders (the government, developmental organisations and people in the locality) of such tourist sites to the cultural landscapes present in the sites (Dalat 2010). This is a similar issue to Venkateswarlu's (2019) observation regarding India's tourism industry. More attention is paid to receiving foreigners, so airports and luxurious hotels are the major concern, rather than intercity terminals and affordable accommodation. We need to address these issues to support the development and subsequent management of the cultural landscapes for tourism, for the sake of posterity and to improve the environmental quality.

Despite abundant research about the nexus between cultural landscape and tourism, as well as the wealth (in terms of tourism prospects) of Abeokuta, there is little or no focus on the assessment of these landscapes and the factors responsible for such assessment. The lack of concrete research in these areas has caused a situation of unavailability of data to prove that these landscapes need more attention from stakeholders. In an attempt to remedy the situation, this paper aims at investigating cultural landscapes in Abeokuta tourist locations by evaluating the fundamental factors, investigating public assessment and expectations of tourist cultural landscapes and to investigate the ways through which cultural landscapes can improve sustainable development in tourism.

\section{Literature Review}

\section{Public Assessment and Expectations of Cultural Landscapes in Tourist Sites}

In the assessment of landscape, landscape quality is defined as including a wide range of environmental/ecological, socio-cultural and psychological factors. Landscape appraisal is a subjective term that describes the study of the effect of landscape changes upon landscape value (The James Hutton Institute (JHI), 2014). The conclusion in Silva's (2017) study on the authenticity of Kandy asserted that periodic assessment of the authenticity of cultural landscapes is essential in the definition of the steps to be taken in the maintenance of the authenticity of such properties.

Several researchers in the past have chosen to follow the objective path in the appraisal of landscape quality, arguing that a set of "experienced and responsible professional subgroup", consisting members of the environmental and design professions, should be saddled with the responsibility of carrying out what they termed landscape evaluation. This study applies a subjective perspective as regards landscape assessment. This direction is mostly informed by Jacques (1980) work, which suggests that a subjective perspective has widespread impact on landscape appraisal and assessment since landscapes have been regarded according to visual tastes and pleasure gained. More so, public involvement in planning and assessment would improve public commitment to the sites, as well as public satisfaction (Lee, Lee, Jeong, Shafer, \& Chon, 2019). The subjectivity of the term implies that the results obtained from this study are based on an individual's perception of the environment. Perception is defined as "the activity carried out by the brain by which we interpret what the senses receive" (Van Heijgen, 2013).

Enhancing the subjectivity of perception is the fact that perception is influenced by three factors, namely physical landscape, culture and individual differences (Van Heijgen, 2013). Furthermore, Van Heijgen (2013) described the physical landscape as the major influence, in that the scenery of the landscape remains the same, regardless of what the observer thinks. This implies that the landscape must first exist before it can be perceived; hence, the physical landscape is the most influential factor that determines the perception of the landscape. Cultural factors are often regarded as those factors that originate from external sources around an individual but directly affect such individual. For example, Taylor \& Lennon (2012) gave politics, social and economic values as social factors that influence one's perception. Shore (2007) gave religion as one of those cultural factors. 
Individual differences such as educational background, hobbies, special interests, sex, and age have different forms of influences on the perception of landscape (Aoki, 1999). These qualities are different for each individual, and they fuse to determine the choices and decisions taken by people.

Over the years, there has been a vital, hypothetical, disagreement of opinion over the question of whether landscapes have an intrinsic or objective beauty which may in some way be measurable or comparable, or whether the visual quality is a value that can only be subjectively attributed to a particular landscape (Xue, 2018). JHI (2014) attributed the objective opinion to physical geographers, stating that these scientists have devised ways of measuring landscape parameters to reflect visual quality; and the subjective nature to the human geographers, who have probed individual and societal attitudes toward the landscape. Arguably, subjective assessment is not only carried out by human geographers since this assessment is mainly based on perception. Subjective assessment is something that any stakeholder of a landscape can carry out, and this involves the general public. This study focuses on the subjective aspect of assessment, especially the perception of stakeholders of these tourist landscapes.

According to Bidegain, López-Santiago, González, Martínez-Sastre, Ravera and Cerda (2020), visual pleasantness of a landscape is based only on user enjoyment. When humans see a landscape, they take in and process information from both the scenery that is under observation and experience of past visual images, leading to the perception of values in such landscapes (Brown \& Brabyn, 2012). For effective public support in landscape management to take place, a proper understanding of these values and contributors to the beauty of specific landscapes. Some of these values were identified by Brown and Brabyn and they include aesthetic or visual pleasantness, recreation, economic ecological, native wildlife, native vegetation, and social values. These values are seen as the essential bases on which individuals carry out their assessment of different landscapes. However, experts and individuals (or groups) that are environmentally inclined would usually assign priority to ecological value (Bidegain, et al., 2020).

\section{Factors Affecting Cultural Landscapes in Tourist Sites}

In a 'state of conservation report' prepared by the World Heritage Committee (WHC) of the United Nations Educational, Scientific and Cultural Organisation (UNESCO), some threats influencing the value of properties in the world heritage list are identified (WHC, UNESCO, 2018). Naturally, when speaking about factors affecting a thing, there should be a balance between those affecting positively and negatively. In the case of cultural landscapes, the WHC focused attention on the factors that constitute a threat to the landscapes. The reason is not far-fetched. All activities that could ultimately affect cultural landscapes positively culminate in effective landscape management. Without proper management strategies, the landscapes keep deteriorating. Hence, it is safe to say that effective landscape management is the major factor that positively affects cultural landscapes (Luekveerawattana, 2012). To develop tourism sustainably, Tuan \& Rajagopal (2019) identified factors under the groupings of environmental - creating prosperity for all societal levels; economical - respecting people's human rights and ensuring equity; and societal (or social) factors - protecting and managing resources.

The various factors that influence landscapes negatively could be conveniently categorized into four different classes (Rigol, 2015). These classes are physical, economic, social and cultural factors. Usually, the social and cultural classes are grouped because of their interconnection. These four classes could also be grouped into subjective factors and objective factors. Subjective factors are factors that are based on or related to attitudes, beliefs or opinions, as opposed to verifiable evidence or phenomena which describe the objective factors. An example of a subjective factor is the ignorance about the importance of heritage properties. This ignorance is on the part of individuals, and it has determined their attitudes to the heritage properties. On the other hand, climate change and weather events are good examples of objective factors. These factors cannot be exactly influenced by man.

Physical factors influencing the landscape manifest in many different forms. Climatic change, as well as severe weather events, could cause a change in the morphology of a property. This also brings into cognizance the impact of natural climatic disasters. Examples are tornadoes, hurricanes, flooding, drought, drastic temperature change, as well as desertification. A poor management system for tourism could lead to excessive, poorly planned or unmonitored tourism activities, which impose an improper level of change on the property. It could also lead to disrespect for the heritage by visitors, which could in turn introduce vandalism, theft, and other violent physical impacts like armed conflicts, looting and illicit trafficking (Brooks, 2018). Terrorist attacks are also physical factors that lead to the deterioration of the properties. Physical factors also include sudden ecological geological events such as volcanoes, earthquake, tsunami, avalanche, landslide, etc. (WHC, UNESCO, 2018). Other physical factors are pollution arising as a result of residential and commercial garbage and solid waste, and the physical extraction of mineral and resources by mining and quarrying.

Concerning economic factors, Habib and Zakeri (2013) enlisted the jobs of most people in the area as a major factor affecting the cultural landscape in Hormoz Island. Fowler's (2008) also highlighted factors such as dependence on market fluctuations and business interests as well as subsidies for products that are dedicated to 
export. Although these factors attract people to the area, they blur (or eliminate) the traditional character of the community, leaving a 'merely' economic and productive function in the area. Other crucial economic factors, which were included in UNESCO's publication include the lack of funds in the region to develop heritage sites, low investment capacity of various investors within and outside the region, improper allocation of funds when available and speculation with land and buildings in the area, which leads to an excessive increase in the price (Rigol, 2015). The lack of funds is a constant problem in relatively poor countries, sometimes arising from the misappropriation or erroneous distribution of these funds.

Social factors are those factors that contribute to the deterioration process of the fabric of heritage sites by the pattern in which people live and carry out their activities, as well as the factors that directly influence the way of life of people dwelling in the local area. On the other hand, cultural factors are those that relate to the traditions and the religious and spiritual value of the place. The intertwined nature of both factor groups has caused that to be linked to each other, to become 'socio-cultural' factors, as observed in WHC, UNESCO's (2018) listing. A typical example is the bad reception of tourists by the host communities in that they cannot properly relate with the foreigners' culture and social demands (Ukabuilu, Nwokorie, \& Ezeibe, 2018). Other examples include poor living conditions for the inhabitants of the area, unavailability of opportunities to study, and inadequate access to basic services and infrastructure, changes in the traditional ways of life, changes in religious and spiritual values, amongst many others.

\section{Cultural Landscapes for Sustainable Tourism Development}

Sustainability is defined as the process of change, in which the exploitation of resources, the direction of investments, the orientation of technological development and institutional change are all in harmony and enhance both current and future potential of mankind to survive in dynamic equilibrium with the environment (Hector, Christensen, \& Petrie, 2014). Kuhlman \& Farrington (2010) defined Sustainability as "maintaining well-being over a long, perhaps even an indefinite period". Sustainability is guided by an organizing principle, which emphasizes the process by which economic growth fosters development. As a result, Sustainable development is defined as "the development path along which the maximisation of the wellbeing of human wellbeing does not compromise perpetual use by future generations" (Ojo \& Oluwatayo, 2016). These definitions depict sustainability as a long-term goal and sustainable development as the introduction or enforcement of conscious change in society to prevent the achieved development from endangering the community in any aspect.

Sustainable development in tourism involves introducing a balance between ecological, economic and social concerns in such destinations. Sustainable tourism is defined as "tourism that respects both local people and the traveller, cultural heritage and the environment" (Fien, Calder, \& White, 2018). Sustainable development of tourist activities is permitted where cultural tourism is concerned (Artal-Tur, Briones-Peñalver, \& VillenaNavarro, 2018). Of the seventeen (17) sustainable development goals (SDGs), tourism is most commonly mentioned in relation to SDGs 8, 12 and 17. These three goals are "Decent Work and Economic Growth", "Responsible Consumption and Production" and "Partnerships for the Goals", respectively. But the World Tourism Organisation and United Nations Development Program (UNWTO \& UNDP respectively) gave guidelines towards achieving sustainable tourism, and stated in the document is that the reach and impact of the tourism industry is so wide that it can, directly or otherwise, contribute meaningfully to the attainment of all 17 goals (UNWTO \& UNDP, 2017). On the flip side, the industry could also significantly harm the environment and disturb social structures if not properly managed. Tuan \& Rajagopal (2019) are of the opinion that it is essential to carefully plan for sustainable tourism right from the start if we are going to positively impact the society as well as preserve resources and culture.

Pavlic, Portolan, and Butorac (2014) gave basic requirements for sustainable tourism, stating that environmental resources must be utilized, the social and cultural values of the resident community should not be abandoned, and it should guarantee long-lasting viability of economic operations. These requirements are regarded as the major principles of sustainable development of tourism, and they are in line with the three dimensions of sustainability highlighted by Paunovic \& Jovanovic (2017). Sustainable tourism should ensure that natural resources are effectively utilized and managed for development purposes, as regards the ecological aspect. In the economic sense sustainable tourism should equally enforce the eradication of methods of production and consumption that cause substantial damage to the environment, as well as those that cannot be maintained at the same rate. Cultures and traditions in these destinations have to be preserved and kept alive as well, and that is the socio-economic responsibility of sustainable development. A balance among the three fields is essential, and the synchrony should be such that the issues that arise in each field are related to the other fields.

Tien, Thai, Hau, Vinh, \& Long (2020) gave principles of sustainable tourism to include the sustainable and appropriate exploitation and use of all resources, reduction of excess consumption and waste, paying adequate attention to the conservation of diversity, conforming development to the socio-economic context of the area, carrying the public and stakeholders along, organising awareness campaigns about environmental resources, and 
effectively marketing the industry. The failure for tourism destinations to adhere with these principles usually result in negative consequences, some of which include degradation of the natural resources of a location, the influx of people into the environment, causing unnecessary pressure on available infrastructure and traffic congestion, damage to the landscape (National Parks, 2018) amongst many others.

For tourism to be truly sustainable there is a need for greater integration and education of the local communities in the development and effective management practices of the tourism site, as well as an exchange of knowledge between stakeholders to ensure the sustainability of landscape management (Moore and Tully, 2018). This shows that more informed stakeholders are likely to shape management strategies that better respond to their needs, and the general involvement of these stakeholders not only gives them a sense of responsibility of the sites but also a sense of belonging and pride attached to the "ownership" of such facilities, and this obliges them to protect and preserve the established facilities. Sustainable and responsible tourism should also be concerned with the education of both staff and tourists, to instil in them the expected visitors' behaviour (Alisa \& Ridho, 2020).

On the completion of the review of the literature about issues relevant to the objectives of this research, a few gaps have been identified, some of which would be described subsequently. The nature of Landscape assessment and appraisal exists in two forms - subjective and objective forms. While the objective assessment is the concern of physical geographers, the subjective arm is determined by how individuals perceive their environment. An understanding of the methods of assessment is necessary, but a bigger necessity is the need to study the relationship between the subjective and the objective opinions, and how they collaborate or come together to improve the quality of the environment, as that is the intended aim of landscape assessment.

Many factors could affect cultural landscapes. Some of these factors fall on the "plus" side, while others are negative. The major disadvantageous ones have been identified, along with the effects they have on the landscapes. The idea of sustainability entails the adequate provision of needs of the present day without jeopardizing the channels through which future needs would be met. Sustainability in tourism hinges more on a balance between ecological, economic and social concerns in tourist destinations. To achieve sustainable tourism, environmental resources must be utilized, the social and cultural values of the resident community should not be abandoned, and it should guarantee long-lasting viability of economic operations. Also, very important is the need to mitigate the effects of the stated factors on the landscapes to bring about a better environment in all ramifications.

The study area, Abeokuta, has a number of published researches on tourism within the area, but generally lacks sufficient literature on the subject of the cultural landscape. Gundele's (2010) paper states that Ogun State (the parent state of Abeokuta) is blessed with a lot of tourism resources, many of which are yet undeveloped. The major point of call for tourism in Abeokuta is the Olumo Rock. Relating to this research, it cannot be automatically concluded that the issues facing landscapes in different cultures and parts of the world would be the same in Abeokuta. This would result in a hasty generalisation fallacy. Further investigation research is carried out to ascertain the factors peculiar to Abeokuta cultural landscapes, as well as how to improve sustainable development in these landscapes, thereby corroborating the literature.

\section{Study Area and Methodology}

The quantitative approach was explored in the research using structured, close-ended questionnaires. Information about the study area such as demographic characteristics, neighbourhoods, knowledge about tourist attractions, as well as their assessment of these tourist attractions, were collected from the respondents. From the questionnaires, respondent opinions were measured on a Likert scale of 5 points, where 5 denotes strongly agree and 1 denotes strongly disagree. The questionnaires were distributed and collected mainly through personal contact with the respondents. The quantitative approach gave room for the data to be presented in numerical terms. A physical visit was also undergone to carry out assessment of two of the sites. The sites visited were Olumo rock tourist complex and Olusegun Obasanjo Presidential Library.

The scope of this research is limited to tourist sites located within Abeokuta. Abeokuta is the capital city of Ogun State. Ogun State is located within Southwest Nigeria and is a Yoruba speaking state (McKenna, Ogun, 2019). Abeokuta is situated on the east bank of the Ogun River, around a group of rocky outcroppings that rise above the surrounding wooded savanna. Abeokuta boasts of several popular tourist sites, namely Olumo Rock, The Ancient Palace of Alake of Egbaland, Olusegun Obasanjo Presidential Library, Federal University of Agriculture, Abeokuta (FUNAAB) zoo and the Adire market (McKenna, Abeokuta, 2019). 


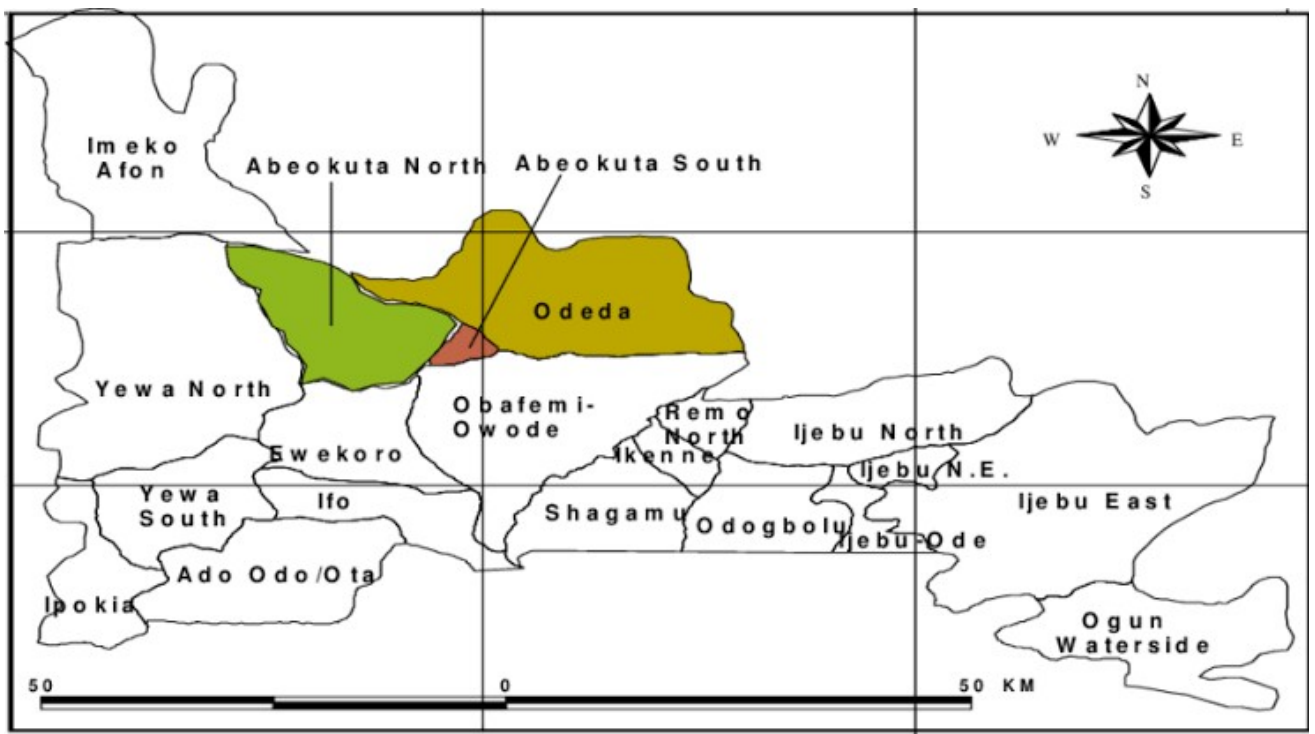

Figure 1: Map of Ogun State showing Abeokuta Metropolis

The population of Abeokuta is narrowed because the major tourist sites in Abeokuta, which form the axes of the research, are located in Abeokuta North and South Local Government Areas. The combined adult population of both Local Government Areas from the 2006 census was put at 235,196 people (Brinkhoff, 2018). A sample size calculator, programmed according to the American Marketing Association formula was used to generate the sample size. Using 235,196 as of the population, a confidence level of 95 percent and a confidence interval of 5, the calculator returned an expected sample size of 384 .

The cluster sampling method was found to be the most efficient, considering the large geographic area covered by Abeokuta (the study area). The cluster sampling involves randomly selecting intact groups (not individuals), within the defined population. These clusters include individuals domiciled around tourist centres; individuals in tourism management positions; visitors of tourist sites; and other citizens of the city (who are also stakeholders). Samples were selected randomly from these clusters The field work was carried out by closely supervised trained research assistants. Of the 384 administered questionnaires, a total of 373 were retrieved at the end of the survey. This implies a total percentage recovery (TPR) of 97.13 percent. This figure is deemed to be good enough to draw out a reasonable conclusion. Data analysed using the Statistical Packages for Social Sciences (SPSS) and results expressed in simple percentages.

\section{Results and Discussion Overview of Sites}

To complement the research methods utilized in the study, a physical visit was made to two of the tourist sites, namely Olumo Rock Tourist Complex and Olusegun Obasanjo Presidential Library. The visits were carried out with an aim of assessing their landscapes as well as significance to tourism.

Olumo Rock Tourist Complex (or simply Olumo Rock as it is popularly called) is one of the popular tourist destinations in Nigeria. The complex is located at the intersection between Ijemo-Alape Road and Ita-Bayinbo Street in Ikija area at the heart of Abeokuta, in Abeokuta North LGA of Ogun state. The rock is an historical monument that provided both a dwelling (shelter) and a fortress (protection) for the people of Egba, who had come to the area in the $19^{\text {th }}$ century, during an inter-tribal war. The rock was turned into a tourist site in 1976. Adeniyi (2020) puts the height of the rock at 137metres above sea level. See figures 2 and 3 


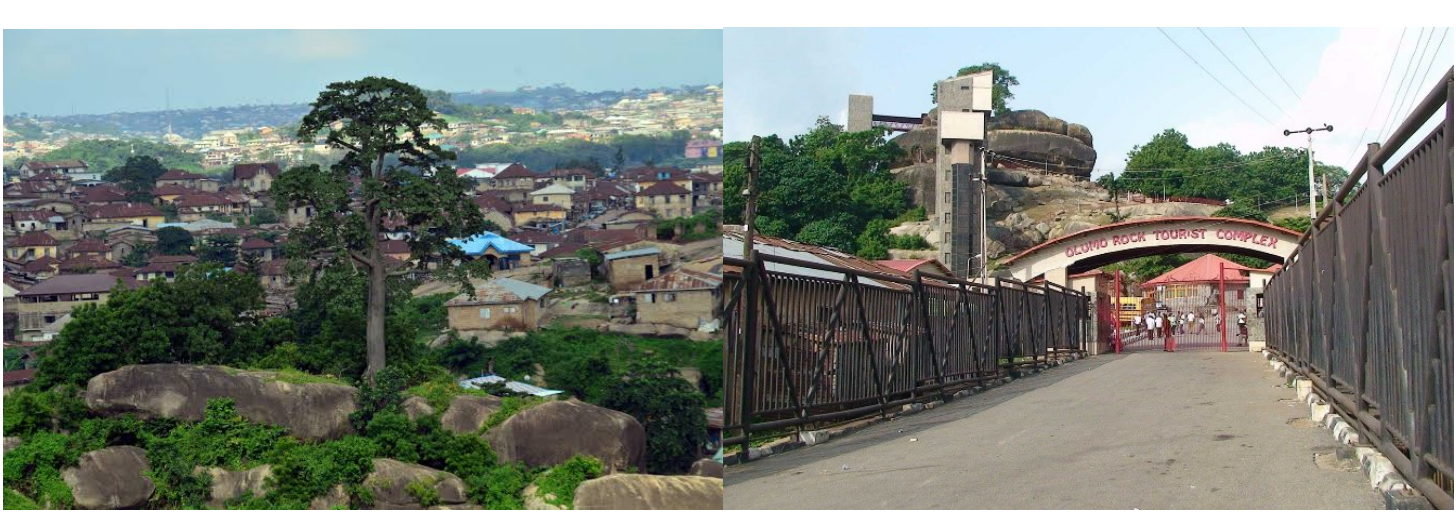

Figure 2: Olumo Tourist Complex

Figure 3: A tree growing on the rock

The rock is a massive outcrop of granite rocks of pre-historic formation, and although it is a natural occurrence, several statues have been erected in the caves. The statues are those of past heroes and warriors, like Lisabi Agbongboakala, Okukenu and Adagba, amongst others. A renovation of the complex in 2006 saw to the installation of a heavy-duty glass escalator running through different levels of the rock, as well as a modern stairway, properly constructed to help tourists reach the top. Presently, the complex houses a water fountain, a restaurant, a conference hall, a multi-purpose hall, and an adire market.

The complex receives a large number of visitors daily, and this number spikes during holidays and festive seasons. Olumo Rock is the prime tourist destination in Ogun state, and it is known to draw tourists from Lagos and other states in Nigeria, as well as from other countries of the world. With a gate fee of $\mathrm{N} 1000$ for every adult visitor, as well as the patronage of other services in the complex, the Ogun State Government receives a large revenue from the sector.

Olusegun Obasanjo Presidential Library, the second site visited, is primarily a historic, touristic, recreational and academic centre, owned by former President of Nigeria, Chief Olusegun Obasanjo. The complex was built with an aim of preserving the historical values of Nigeria. A wide range of activities take place within the complex, and the facilities present include the presidential library, a museum, a resort, a wildlife park, archaeological sites and rocks of inspiration, a bamboo grove bar and restaurant, an amusement park, a hotel, a cinema, a 1500-seater capacity hall, a church and a mosque.

The complex is located on about thirty-two (32) hectares of land, and the landscape has various physical features. The main presidential library is located at the top of a hill, from where a good portion of the beautiful scenery of Abeokuta can be seen. There is also a large rock outcrop around the hilly area, with steps leading to the top. The bamboo grove is located in a valley area with a stream flowing nearby, and the area is designated for relaxation, with bars and restaurants located there. The amusement park is located on a relatively flat terrain, and children carry out their fun activities there. There is a lake for boat rides, and there are swimming pools located at the resort and hotel. The OOPL Wildlife Park is the zoological garden that houses over 140 animals. The garden is situated along the rocky terrain of the complex, and it is intended to promote wildlife conservation. Generally, the interplay of land formations and physical features, together with nice building structures, makes the whole environment a great place to be. See figures 4 and 5

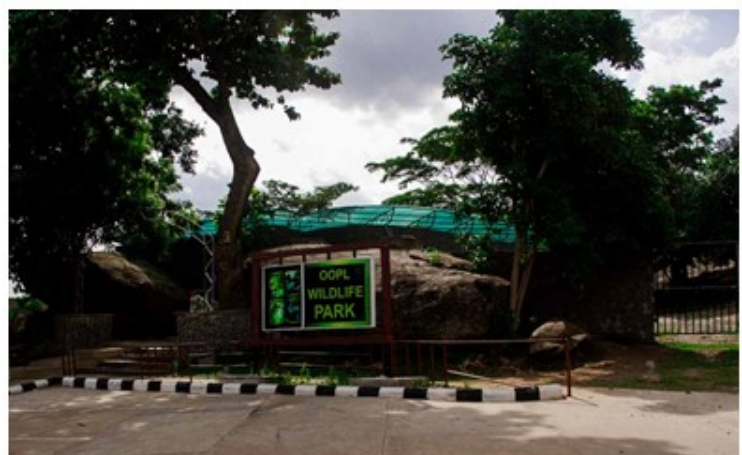

Figure 4: Entrance to the Wildlife Park

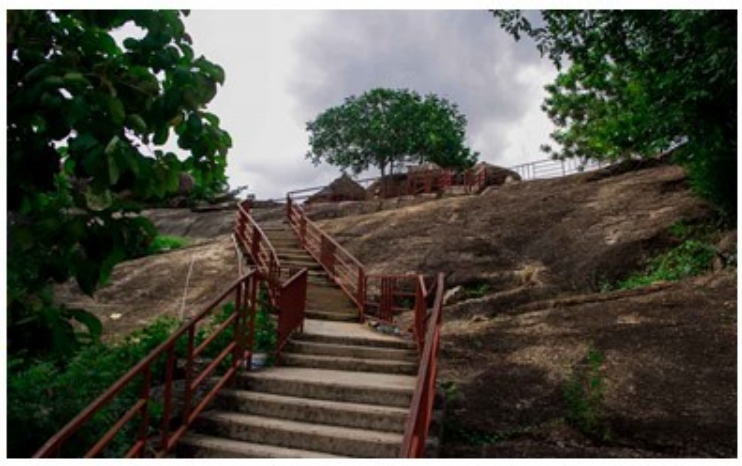

Figure 5: Steps to the top of the rock

Results from the analysis of the characteristics of the respondents using the SPSS showed that a greater number of the respondents are males representing 57.1 percent, while 42.9 percent are females. This implies that a greater percentage of the information was sourced through men. The study also revealed that 36.7 percent of the respondents are within the age bracket of 18-30 years, 26.5 percent fall within the group of 31-40 years, 24.7 
percent and 10.5 percent are within the age brackets of 41-50 and 51-60 respectively, and respondents older than 60 years of age was recorded as 1.6 percent. Furthermore, the bulk of the respondents were working-class people, with only 29.3 percent being students, and 7.1 percent being unemployed. This may be because the study area is a state capital (Abeokuta, Ogun state) and state capitals are usually the centres of economic activities. They also usually have the concentration of manufacturing industries, as well as a huge workforce in the public and private sectors.

Regarding the level of educational attainments of the respondents, a great percentage (86.4 percent) had one form of tertiary education or the other. This reveals that most of the respondents were literate enough to answer the questions correctly. Those who attended primary school through secondary school constitutes 11.0 percent, 1.0 percent stopped at the primary school level, while 1.6percent had no form of formal education. This indicates that their responses and sense of judgment can be relied upon, based on their level of understanding and exposure. The range of income level was also ascertained through the survey, with 31.5 percent of the respondents earning between $\$ 30,001$ and $\$ 100,000$ monthly; 25.2 percent earn less than $\$ 30,000 ; 26.9$ percent earn between $\mathrm{N} 100,001$ and $\mathrm{N} 500,000$; while 6.2 percent earn above $\mathrm{N} 500,000$. However, 10.2 percent of the respondents did not answer this question. Data on religion was collected also, and this reflected that 41.3 percent of the respondents are Christians, 31.7 percent are Muslims and the remaining 27.0 percent claimed to be traditionalists.

Respondents were asked further questions, including the extent of the impact of some factors on the landscapes, their assessments of the landscapes, as well as questions relating to the sustainable development of the landscapes. The questions asked and responses are further discussed below.

Factors Affecting Cultural Landscapes

The extent of the effect of some factors on the landscapes was investigated. The study focuses on the impact of the following factors on the properties: Natural disasters, Vandalism and tourism, and Poor management.

Based on how much natural disasters and environmental hazards affect cultural landscapes, respondents were asked to rate their responses from very high to very low. Table 1 reveals that 24.7 percent (95) agree that cultural landscapes are affected by natural disasters at a very high rate, and 14.1 percent (54) believe that the rate is fairly high. Also, 16.4 percent (64) think the effect is at a very low rate and 18.2 percent (70) chose fairly low. On the other hand, 25.3 percent think the effect is on the average level, and a total of 4 respondents did not answer to that question. It, therefore, implies that a total of 38.8 percent of respondents agree that the effect is higher than average, and 34.9 percent think that the effect is less than average.

Table 1: Table showing the result of "natural disasters"

\begin{tabular}{|lcr|} 
& Frequency & Percent \\
\hline very high & 95 & 24.7 \\
fairly high & 54 & 14.1 \\
average & 97 & 25.3 \\
fairly low & 70 & 18.2 \\
very low & 64 & 16.7 \\
Total & 380 & 99.0 \\
Missing & 4 & 1.0 \\
Total & 384 & 100.0 \\
\hline
\end{tabular}

Table 2, showing the degree of impact of vandalism and terrorism, reveals that 21.6 percent (83) agree that cultural landscapes are affected by vandalism and terrorism at a very high rate, and 21.1 percent (81) believe that the rate is fairly high. Also, 21.4 percent (82) think the effect is at a very low rate and 13.5 percent (52) chose fairly low. On the other hand, 20.8 percent (80) think the effect is on the average level, and a total of 6 respondents did not answer to that question. It, therefore, implies that a total of 42.7 percent of respondents agree that the effect is higher than average, and 34.9 percent think that the effect is less than average.

Table 2: Table showing the result of "vandalism and terrorism"

\begin{tabular}{lcr}
\hline & Frequency & Percent \\
\hline very high & 83 & 21.6 \\
fairly high & 81 & 21.1 \\
average & 80 & 20.8 \\
fairly low & 52 & 13.5 \\
very low & 82 & 21.4 \\
Total & 378 & 98.4 \\
Missing & 6 & 1.6 \\
Total & 384 & 100.0
\end{tabular}

For poor management, table 3 shows that 33.6 percent (129) agree that cultural landscapes are affected at a very high rate, and 20.1 percent (77) believe that the rate is fairly high. Also, 6.8 percent (26) think the effect is 
at a very low rate and 9.6 percent (37) chose fairly low. On the other hand, 28.9 percent (111) think the effect is on the average level, and a total of 4 respondents did not answer to that question. It, therefore, implies that a total of 53.7 percent of respondents agree that the effect is higher than average, and 16.4 percent think that the effect is less than average.

\begin{tabular}{lcc} 
Table 3: Table showing the result of "poor management" & Frequency & Percent \\
\hline very high & 129 & 33.6 \\
fairly high & 77 & 20.1 \\
average & 111 & 28.9 \\
fairly low & 37 & 9.6 \\
very low & 26 & 6.8 \\
Total & 380 & 99.0 \\
Missing & 4 & 1.0 \\
Total & 384 & 100.0 \\
\hline
\end{tabular}

The survey returned a general view that the analyzed factors have significant effects on the cultural landscapes, hence it could be said that the factors affecting landscapes which were identified in the literature review section are also active in tourist sites of Abeokuta.

Public Assessment of Cultural Landscapes

In this section, several parameters were addressed in consideration of how members of the general public, who constitute a part of the stakeholders of such tourist sites, appraise the cultural landscapes. In the questionnaire, respondents were asked to grade on a scale of 1 to 5 ( 1 being the least and 5 the highest), their assessment of the landscapes under different categories. The data were analyzed using the frequency of each variable, and the result is shown in tables 4-6 below.

From the questionnaires distributed, visual pleasantness of the site was based on how good-looking the site are, and the presence and impacts of adequate amenities. Numbers from table 4 show that 46 people (12.0 percent) are very pleased with the visual quality of the sites, giving a high rating, and 68 people (17.7 percent) are fairly pleased with how the site looks, giving a rating of fairly high. Some respondents gave an indifferent reaction about their perception of the sites, and this group consists of 93 people, making up 24.2 percent of the valid responses received. Another set of respondents, numbered 64 (16.7 percent), gave low ratings, while 104 people (27.1 percent) rated them as fairly low.

Table 4: Table showing the result of the public assessment of visual pleasantness of site

\begin{tabular}{lcr}
\hline & Frequency & Percent \\
\hline High & 46 & 12.0 \\
Fairly high & 68 & 17.7 \\
Neutral & 93 & 24.2 \\
Fairly low & 104 & 27.1 \\
Low & 64 & 16.7 \\
Total & 375 & 97.7 \\
Missing & 9 & 2.3 \\
Total & 384 & 100.0 \\
\hline
\end{tabular}

Table 5 gives the result deduced from the questionnaires about how encouraging these sites are to visit. From the table, 9.6 percent ( 37 people) and 9.1 percent (35 people) selected high and very high respectively, meaning that they feel encouraged in one way or the other to keep visiting the sites. 104 respondents (27.1 percent) stood on neutral ground and picked the neutral option. 142 people (37.0 percent) selected fairly low, and the remaining 14.3 percent (55 people) selected low. It, therefore, implies that a total of 18.7 percent gave the sites a rating higher than average, and 51.3 percent think that the encouragement to return to the site is less than average. This result corroborates Ajibode and Aako's (2017) research which stated that the tourist patronage to Olumo Rock will continue to decline with seasonal effect as time goes on. People are not as motivated as they once were to visit these sites.

Table 5: Table showing the result of the public assessment of the level of encouragement to visit sites

\begin{tabular}{lcr} 
& Frequency & Percent \\
\hline High & 37 & 9.6 \\
Fairly high & 35 & 9.1 \\
Neutral & 104 & 27.1 \\
Fairly low & 142 & 37.0 \\
Low & 55 & 14.3 \\
Total & 373 & 97.1 \\
Missing & 11 & 2.9 \\
Total & 384 & 100.0 \\
\hline
\end{tabular}


Maintenance to a tourist site brings about a constant renewal of the cultural landscape, enabling it to sustain its originality and authenticity. Table 6 , giving the result of the level of maintenance of these locations, shows that 8.1 percent (31) and 18.8 percent (72) selected high and very high respectively, meaning that they feel encouraged in one way or the other to keep visiting the sites. 126 respondents (32.8 percent) stood on neutral ground and picked the neutral option. 103 people (26.8 percent) selected fairly low, and the remaining 9.6 percent (37) selected low. 15 questionnaires were returned with the space for this question being empty. It, therefore, implies that a total of 26.9 percent gave the sites a rating higher than average, and 35.4 percent think that the level of maintenance is less than average.

Table 6: Table showing the result of the public assessment of the level of maintenance of sites

\begin{tabular}{lcr} 
& Frequency & Percent \\
\hline High & 31 & 8.1 \\
Fairly high & 72 & 18.8 \\
Neutral & 126 & 32.8 \\
Fairly low & 103 & 26.8 \\
Low & 37 & 9.6 \\
Total & 369 & 96.1 \\
Missing & 15 & 3.9 \\
Total & 384 & 100.0 \\
\hline
\end{tabular}

A separate analysis was carried out to investigate the relationship between the visual pleasantness of the locations and poor management, which has been identified as a factor affecting cultural landscapes, using the Chi-squared test. The analysis is presented in a table as shown below. From research works of literature reviewed, the general academic opinion suggests that management is a critical factor in the tourism industry, and table 7 below shows that the opinion of residents, who happen to be stakeholders, is in sync with the academia. Hence, poor management determines, by a long shot, how good-looking the landscape would be.

Table 7: Table showing the result of "visually pleasant" against "poor management"

$\begin{array}{lccc} & \text { Value } & \text { df } & \text { Asymp. Sig. (2-sided) } \\ \text { Pearson Chi-Square } & 34.712^{\mathrm{a}} & 20 & .000 \\ \text { Likelihood Ratio } & 34.254 & 20 & .000 \\ \text { Linear-by-Linear Association } & 1.768 & 1 & .011 \\ \text { N of Valid Cases } & 371 & & \\ \text { a. } 4 \text { cells (20.0 percent) have expected count less than 5. The minimum expected count is .50 }\end{array}$

There is a significant association between "visual pleasantness" and "poor management". This gives an understanding that inadequate or poor management practices have a direct influence on how the sites look, according to information retrieved from the respondents. As deduced from literatures reviewed, a poor management system for tourism could lead to excessive, poorly planned or unmonitored tourism activities, which could impose an improper level of change on the property. In a poor management system, some developments could even be carried out on the sites. But these efforts are easily frustrated because there is neither continuity nor maintenance.

The importance of this inference to the tourism industry is the availability of proof of the negative influence of poor management on tourist sites. In practical terms, bad management would give room for mechanical equipment, for example, to get completely bad before any intervention would take place. When repairs would eventually be carried out, a lot more expenses would go into it, than if it had been properly maintained from the onset. This calls for better management practices to be carried out on tourist attractions. This can be made possible by the effective participation of stakeholders. All stakeholders should be properly sensitized and brought into the realisation that either directly or indirectly, effective management rests on their shoulders. The government should also play its own part in ensuring that adequate funding is provided, and that related policies are properly enforced.

Cultural Landscapes and Sustainable Development

The concluding section of the questionnaire contains questions relating to the trending issue of sustainable tourism development. This was carried out in a bid to investigate the ways through which cultural landscapes can improve sustainable development in tourism. Respondents were asked if cultural landscapes, when effectively developed and maintained, had the possibility of improving different aspects of life, such as the health of occupants and residents of the area, the quality of their lives, the possible economic benefits and aesthetics of the environment. The table 8 below shows the details of the analysis. 
Table 8: Table showing the result of cultural landscapes and sustainability (using mean and median)

\begin{tabular}{|c|c|c|c|c|c|}
\hline & $\begin{array}{l}\text { Improve } \\
\text { health of } \\
\text { occupants }\end{array}$ & $\begin{array}{c}\text { Improve the } \\
\text { quality of life of } \\
\text { people }\end{array}$ & $\begin{array}{c}\text { Bring beauty to } \\
\text { the } \\
\text { environment }\end{array}$ & $\begin{array}{c}\text { Generate } \\
\text { employment } \\
\text { opportunities }\end{array}$ & $\begin{array}{l}\text { Attract huge } \\
\text { investments }\end{array}$ \\
\hline Valid & 378 & 378 & 377 & 380 & 380 \\
\hline Missing & 4 & 4 & 5 & 2 & 2 \\
\hline Mean & 4.25 & 4.18 & 4.63 & 4.55 & 4.52 \\
\hline Median & 4.00 & 4.00 & 5.00 & 5.00 & 5.00 \\
\hline
\end{tabular}

The table establishes that the respondents, on the average, agree that the development of cultural landscapes can improve the health of the occupants of the environment, the quality of life of people, can bring visual pleasantness to the environment, can generate employment opportunities and can attract huge investments.

In recent times, urban tourism areas have been faced by continuously-accumulating burden on their natural, cultural and socio-economic environments due to the speedy growth of the tourism industry. Uncontrolled tourism development ultimately degrades the attractive natural and cultural features of the place and thus, cannot sustain the basic resources on which it relies. Key findings from the works of literature reviewed all posit that effectively managed landscapes have a form of a contribution to sustainable development. This is pointed out in the works of Ayeni (2012), Luekveerawattana (2012), Paunovic \& Jovanovic (2017), as well as Pavlic, Portolan, $\&$ Butorac. The findings from this study are in line with these literatures, and also shows that the stakeholders are properly aware of the negative effects of the discriminate use of the tourist sites, and the extent to which proper management and use of the sites can positively influence toe environment and the economy.

\section{Conclusion}

An outstanding cultural landscape found anywhere is a good attraction to many tourists. In the case of Abeokuta, these cultural landscapes include Olumo Rock Tourist Complex, the Alake's Palace, Ake, Olusegun Obasanjo Presidential Library, Federal University of Agriculture, Abeokuta (FUNAAB) zoo, and the Adire Market in Itoku. All of these tourism destinations tell stories of what was going on in the past and what is going on in the present.

To take tourism to the next level in Nigeria, it is necessary that each resolution concerning the destination is well constructed and ruminated upon, keeping in mind the question: "What effects or consequences will this decision have in the future in a wide range of fields?" The answer to this question is as a result of the ability of the decision makers to be well-versed and conversant with issues relating to the landscape, make up-to-date choices, and take remedial actions based on interdisciplinary, collaborating processes and not to act as a one-way street or dwell on one narrow line of imagination.

Overall, Poor maintenance has the greatest negative effect on cultural landscapes in Abeokuta. Apart from poor maintenance, "Natural disasters" and "Vandalism and Terrorism" also affect these landscapes, and prevent tourists from visiting the sites. The above-mentioned factors mainly affect the visual pleasantness of the landscapes. Maintenance of available cultural landscapes is generally bad, bringing about a decline in the development of tourism in Abeokuta. Stakeholders are conversant with the contributions of 'prospering' tourism industry to sustainable development.

\section{Recommendations}

This research investigated the fundamental factors affecting cultural landscapes in tourist sites, public assessment, and expectations of tourist cultural landscapes and the ways through which cultural landscapes can improve sustainable development in tourism. The study, which was limited to the collection of data used for analysis in Abeokuta, makes the result to be sufficient for generalisation in Abeokuta city. It is important to investigate other locations of major tourist attractions in Nigeria to verify the existing beliefs and theories held by researchers.

- The study recommends better participation and involvement of stakeholders of all tourist sites in the activities, as a balanced level of positive participation by all parties eventually result in the effective management of the landscapes. This is made possible if these stakeholders are properly sensitized and brought into the realisation that either directly or indirectly, effective management rests on their shoulders;

- Sustainable development is achievable only by relating and creating interaction between cultural characteristics and environmental inclinations, taking into account the existing economy all in a bid to avoid endangering the future. To attain the goal of sustainable development the following recommendations are suggested;

- Provision of good roads to ease access to locations, encouraging more people to visit;

- Authorities have to identify the significance of design and imaginative ingenuity, that the design role covers many aspects of a tourist-friendly community, including urban design, design of pedestrian areas, materials and interface, suitable car park, transportation and related facilities, visitor facilities, information booths, 
kiosks and the likes, street furniture, heritage trails and signages; and

- Transportation has to be cheap to be attractive and must primarily serve the local need.

\section{Limitations}

This study has a number of limitations, including the availability of data, as well as its accuracy, which could not be influenced by the researchers. There is a possibility that some factors studied, although significant in some areas, have not had substantial influence on the other sites. The study has also not investigated the extent to which these factors affect the landscapes, and whether one is more dominant in a site, and a different one in another site. Future research should further explore this matter. Research on the impacts of both improved and declined tourism in the studied locations on other aspects of life apart from the economy would also be beneficial in educating stakeholders on the importance of properly managing the tourism sector.

\section{References}

Adeniyi, E. (2020, June 2020). Olumo Rock: History, Location, Gate Fee, Accommodation in 2020. Retrieved from PropertyPro Web site: www.propertypro.ng/blog/olumo-rock-hostory-location-gate-feeaccommodation/

Ajibode, I., \& Aako, O. (2016). Time Series Modelling of Tourists Traffic at Olumo Rock. Conference Paper.

Alisa, F., \& Ridho, Z. (2020). Sustainable Cultural Tourism Development: A Strategic For Revenue Generation in Local Communities. Journal of Economic and Tropical Life Science (JETLS) (2020) Vol. 4 No. 2., pp.4756.

Aoki, Y. (1999). Review article: Trends in the study of the psychological evaluation of landscape, Landscape Research, 24, 85-94.

Artal-Tur, A., Briones-Peñalver, A. J., \& Villena-Navarro, M. (2018). Tourism, cultural activities and sustainability in the Spanish Mediterranean regions: A probit approach. Tourism \& Management Studies, 14(1), 7-18.

Ayeni, D. A. (2012). Enhancing the Nigerian Tourist Attractions through Landscaping for Sustainable Tourism Development. American Journal of Tourism Research Vol. 1, No. 2, 2012, 59-66.

Bankole, A. O. (2013). Harnessing Cultural Heritage for Tourism Development in Nigeria: Issues and Prospects. Global Journal of Commerce and Management Perspective, Vol. 2(3), 121-131.

Bidegain, Í., López-Santiago, C. A., González, J. A., Martínez-Sastre, R., Ravera, F., \& Cerda, C. (2020). Social Valuation of Mediterranean Cultural Landscapes: Exploring Landscape Preferences and Ecosystem Services Perceptions through a Visual Approach. Land 2020, 9, 390.

Brinkhoff, T. (2018, August 21). Abeokuta South. Retrieved from City Population: https://www.citypopulation.de/php/nigeria-admin.php?adm2id=NGA028002

Brown, G., \& Brabyn, L. (2012). An analysis of the relationships between multiple values and physical landscapes at a regional scale using public participation GIS and landscape character. Landscape and Urban Planning 107 (2012), 317-331.

Çakmak, E., \& Çenesiz, M. A. (2020). Measuring the size of the informal tourism economy in Thailand. International Journal of Tourism Research, Volume22, Issue5, 637-652.

Crotti, \& Misrahi, T. (2017). The Travel and Tourism Competitiveness Report 2017. World Economic Forum. Geneva.

Dalat G. (2010). Developing Rural based tourism as a strategy for rural development in Nigeria; Int. J. Creativity Tech. Dev. 2:1-3

Fien, J., Calder, M., \& White, C. (2018, July 8). Sustainable Tourism. Retrieved from UNESCO - Teaching and Learning for a Sustainable Future: http://www.unesco.org/education/tlsf/mods/theme_c/mod16.html

Fowler, Peter. (2008). Landscapes for the World -- Conserving a global heritage. Windgather Press, Cheshire, UK, 2008.

Habib, F., \& Zakeri, H. (2013). Analyzing Factors Affecting Formation of Cultural Landscape in Hormoz Island. Advances in Environmental Biology 7(6), 988-998.

Hector, D., Christensen, C., \& Petrie, J. (2014). Sustainability and Sustainable Development: Philosophical Distinctions and Practical Implications. Environmental Values 23, February 2014, 7-28.

Jacques, D.L. (1980) Landscape Appraisal: The Case for a Subjective Theory. Journal of Environmental Management, 10, 107-113.

Jansirami S. and Mangai, (2013). Industrial Tourism: An Introduction. IOSR Journal of Business and Management. 9(4), pp 12-14.

Kaya L. G. (2002). Cultural Landscape for Tourism. ZKÜ Bartın Orman Fakültesi Dergisi

Kuhlman, T., \& Farrington, J. (2010). What is Sustainability? Sustainability ISSN 2071-1050.

Lee, J., Lee, H.-S., Jeong, D., Shafer, C. S., \& Chon, J. (2019). The Relationship between User Perception and Preference of Greenway Trail Characteristics in Urban Areas. Sustainability 2019, 11, 4438. 
Luekveerawattana, S. (2012). Cultural Landscape for Sustainable Tourism - Case Study of Amphawa Community. Procedia - Social and Behavioral Sciences 65 (2012), 387 - 396.

McKenna, A. (2019, July 1). Abeokuta. Retrieved from Encyclopaedia Britannica: https://www.britannica.com/place/Abeokuta

McKenna, A. (2019, July 1). Ogun. Retrieved from Encyclopaedia Britannica: https://www.britannica.com/place/Ogun-state-Nigeria

Moore, T., \& Tully, G. (2018). Connecting landscapes: examining and enhancing the relationship between stakeholder values and cultural landscape management in England. Landscape Research 43:6, 769-783.

National Park Service (NPS). (2014). "Defining Landscape Terminology / Cultural Landscape Guidelines." NPS. U.S. Department of the Interior, n.d. Web. 2014. <http://www.nps.gov/tps/standards/fourtreatments/landscapeguidelines/terminology.htm>

National Parks. (2018, July 7). The impacts of tourism. Retrieved from National Parks, UK: http://www.nationalparks.gov.uk/students/ourchallenges/tourism/impactsoftourism

Nations Encyclopedia (2018, June 3). Nigeria. Retrieved from Encyclopedia of the Nations: http://www.nationsencyclopedia.com/economies/Africa/Nigeria.html

Naveh, Z., \& Lieberman, A. S. (2013). Landscape Ecology: Theory and Application. Springer Science \& Business Media.

Ojo, A. O., \& Oluwatayo, I. B. (2016). Drivers and Challenges of Sustainable Development in Africa. 3rd International Conference on African Development Issues (CU-ICADI 2016) ISSN:2449-075X.

Pacione, M. (2003). Urban environmental quality and human wellbeing: A social geographical perspective. Landscape and Urban Planning, 65, 19-30.

Paunovic, I., \& Jovanovic, V. (2017). Implementation of Sustainable Tourism in the German Alps: A Case Study. Sustainability 2017, 9, 226.

Pavlic, I., Portolan, A., \& Butorac, M. (2014). Urban Tourism towards Sustainable Development. International Journal of Multidisciplinarity in Business and Science, Vol. 1, No. 1.

Richards, G. (2018). Cultural Tourism: A review of recent research and trends. Journal of Hospitality and Tourism Management, Volume 36, 12-21.

Rigol, I. (2015). Management of Cultural Landscapes. Havana: UNESCO.

Shore, N. (2007). 'Whose Heritage? The Construction of Cultural Built Heritage in a Pluralist Multicultural England', unpublished PhD thesis, Newcastle University.

Silva, K. D. (2017). The symbolic authenticity of Kandy, Sri Lanka. In K. D. Silva, \& S. Amita, Cultural Landscapes of South Asia (pp. 144-158). New York: Routledge.

Song, W., St. Clair, R. N., \& Wang, S. (2008). Modernisation and the sedimentation of cultural space of Harbin: The stratification of material culture. Intercultural Communication Studies, XVII(1), 22-37.

Taylor, K. \& Lennon, J. (2012). Managing Cultural Landscapes. Routledge, Abingdon

The James Hutton Institute, (2014) Review of Existing Methods of Landscape Assessment and Evaluation. www.macaulay.webarchive.hutton.ac.uk/ccw/task-two/evaluate.html\#null Assessed on June 2, 2018.

Tien, N. H., Thai, T. M., Hau, T. H., Vinh, P. T., \& Long, N. V. (2020). Solutions for Tuyen Quang and Binh Phuoc tourism industry sustainable development comparative analysis. International Journal of Research in Marketing Management and Sales 2020; 2(1), 101-107.

Tuan, V. K., \& Rajagopal, P. (2019). Analyzing Factors affecting Tourism Sustainable Development towards Vietnam in the New Era. European Journal of Business and Innovation Research, Vol.7, No.1, pp.30-42.

Ukabuilu, E., Nwokorie, E., \& Ezeibe, N. (2018). Empirical Investigation of Problems of Inbound Tourism in Southeastern Nigeria: Catalyst For Regional Development. HATMAN Journal of Hospitality \& Tourism, Vol. 8 No. 1, 29-35.

van Heijgen, E. (2013). Human Landscape Perception. UK: Wageningen University.

Venkateswarlu, P. (2019). Prospects and problems of tourism in India. International Journal of Business, Economics \& Management, 2(1), 38-41.

WHC, UNESCO. (2018, July 10). List of factors affecting the properties. Retrieved from UNESCO World Heritage Centre: https://whc.unesco.org/en/factors/

World Tourism Organisation and United Nations Development Program (2017), Tourism and the Sustainable Development Goals-Journey to 2030, UNWTO, Madrid

Xue, F. (2018, March 13). Two Types of a Doctrine of Objectivity in the Aesthetic Appreciation of Nature. Retrieved from Contemporary https://contempaesthetics.org/newvolume/pages/article.php?articleID=798

Aesthetics: 